\title{
Morphometric Study of Hyoid Bone and its Forensic Implication
}

\author{
Kapil Amgain ${ }^{1}$, Shalikram Adhikary², Paras Thapa ${ }^{3}$, Kamal Raj Sharma², Sujana Neupane 5
}

\author{
Author Info: \\ ${ }^{1}$ Assistant Professor, \\ 2Professor; Department of \\ Clinical Anatomy \& Cell \\ Biology, Karnali Academy of \\ Health Sciences, Jumla \\ ${ }^{2}$ Lecturer, Army Medical \\ College and Teaching \\ Hospital, Kathmandu \\ ${ }^{3}$ Lecturer/Tutor, Hind Institute \\ of Medical Sciences, Ataria, \\ Sitapur, UP, India \\ ${ }^{4}$ Manmohan Cardiothoracic \\ and Vascular Transplant \\ Center, Maharajgunj \\ Kathmandu
}

\section{Corresponding Author: \\ Dr. Kapil Amgain \\ Email/Contact:}

dr.kapilamgain@gmail.com

\section{ABSTRACT}

Background: Hyoid bone, the bone of the anterior midline of the neck, is significant in forensic medicine as it presents the sexual dimorphism. The main aim of this study was to assess the morphometry of hyoid bone and its relationship with sex and height of an individual.

Methods: This was a cross-sectional study, conducted on 60 hyoid bones (36 male and 24 female) in the Department of Anatomy from the year 2013 to 2016 AD. The ethical approval was taken from the department. The 12 major anthropometric measurements were taken on each hyoid bone using a digital Vernier Caliper, and electronic weighing machine.

Result: Total of 60 hyoid bones were studied in this study, out of which 36(60\%) were male. The average measurements of all 12 major parameters of the hyoid bone were found to be significantly greater in male than in female. Moreover, the length of the cadaver (height) had significant correlation with the vertical breadth and transverse length of the body of hyoid bone. The average length of right greater cornu in male and females were $32.78+2.44 \mathrm{~mm}$ and $28.89+2.47$ $\mathrm{mm}$ respectively. The width of the body of the hyoid bone in the midline in male and female were $22.51+3.73 \mathrm{~mm}$ and $20.27+1.75 \mathrm{~mm}$ respectively. The anteroposterior thickness of the body in male and female were $5.66+0.97 \mathrm{~mm}$ and $6.45+1.79 \mathrm{~mm}$ respectively. It was also observed that the hyoid bone was heavier in male $(1.858+0.433 \mathrm{gm})$ than in females $(1.261+0.102 \mathrm{gm})$.

Conclusion: All the anthropometric measurements of hyoid bone were significantly greater in males than in females. Moreover, the height of the person had strong positive correlation with the vertical breadth and transverse length of the body of the hyoid bone. These findings can be used for forensic investigation as well as archeological studies. with high degree of accuracy for the purpose of sex identification.

Keywords: Anthropometry, Cornu, Sexual dimorphism, Osteometry

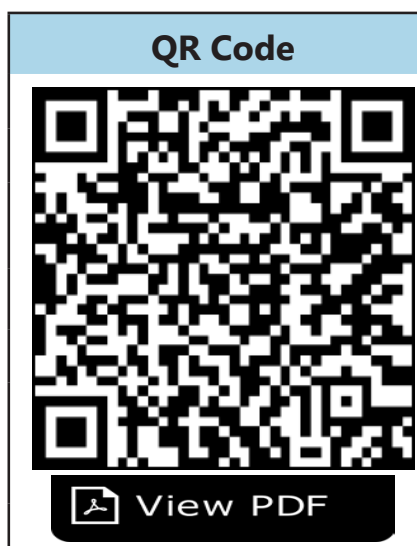

Scan Me for Full Text

\section{Article Info}

Received: 11 December 2019; Accepted: 2 March 2020; Published Online: 3 March 2020 How to cite this article in Vancouver Style?

Amgain K, Adhikary S, Thapa P, Sharma KR, Neupane S. Morphometric Study of Hyoid Bone and its forensic implication. Europasian J Med Sci.2020; 2(2):1-7. https://doi.org/10.46405/ejms.v2i1.28

\section{Disclaimer:}

Conflict of Interest: None Declared;

Source of Support: Nil

Copyright: (C) 2020 by author(s). This is an open access article distributed under the terms of the Creative Commons Attribution International License $4.0 @$ @ - w wich permits unrestricted use, distribution, and reproduction in any medium, provided the original work is properly cited.

\section{Publisher's Note:}

The Europasian Journal of Medical Sciences (EJMS) remains neutral with regard to jurisdictional claims in published articles and institutional affiliations. 


\section{INTRODUCTION}

Hyoid bone, only ' $U$ ' shaped peculiar bone of anterior midline of neck, do not have bony articulation and is distantly articulated to others bone by ligaments and muscles. It is supported by stylohyoid ligaments from the tips of the styloid process of temporal bone. ${ }^{1}$ It has an irregular, elongated and quadrangular body and a pair of horn-shaped projections from the body called greater cornua, and a pair of conical projections at the junction of body and greater cornu is called lesser cornua. ${ }^{2}$ Embryo logically, the lesser cornua is developed from cartilages of second pharyngeal arch and the greater cornua is developed from cartilages of third pharyngeal arch, whereas the upper part of body is developed from second and lower part of body is developed from cartilages of third pharyngeal arch. It has six ossification centers, two for body and one for each cornu. ${ }^{1}$

It is also called an unsocial bone as it doesn't form any joint directly with other bones. However, five pairs of hyoid muscles (geniohyoid, sternohyoid, mylohyoid, omohyoid, stylohyoid), three pairs of tongue muscles (genioglossus, chondroglossus and hyoglossus), one pair of pharyngeal muscles (middle constrictor of pharyngeal), and one pair of ligaments (stylohyoid ligaments) fix this unsocial bone in between the tongue root and thyroid cartilage. It is situated at the level of the fourth cervical vertebra and articulates with surrounding structures via suprahyoid and infrahyoid groups of muscles and ligaments. ${ }^{1-3}$

Determination of sex by the analysis of isolated human skeletal has accuracy ranging from 80$95 \%$ depending on which bone is used to identify the sex. The accuracy of sex identification from human pelvis is $95 \%$ whereas from the skull $92 \%$ accuracy. ${ }^{4,5}$ The metric analysis of the hyoid bone is a helpful technique in the sex determination of a skeleton. 5,6 The hyoid is rarely if ever considered to be a bone that can aid in sex estimation. ${ }^{7}$ However, this study has determined the presence of considerable sexual dimorphism in hyoids and can be used within multiple scenarios and which utilize measurements that can be quickly and easily reproduced. This will provide the physical anthropologist with the opportunity to make use of every skeletal element present when assessing the sex of an individual.

Most of the times, the criminal investigation remains difficult and doubtful due to inaccurate and misleading information or minimum forensic evidence. Study of human skeletal by trained forensic anthropologist can provide utmost light in such cases. ${ }^{8}$ Sex Identification from the remains of human skeletal is a critical component and has greater significance in the forensic medicine for the investigation of criminal history and plays a more key role in solving the medico-legal disputes. ${ }^{9}$

Many researches have been conducted by radiographic ${ }^{6,10}$ as well as photographic ${ }^{11}$ techniques to study the morphology of hyoid bone. However, taking measurements from a radiograph or photograph can be problematic due to dimensional distortion resulting from the angle at which the photograph was taken ${ }^{12}$. So, we performed cadaveric study to find out the exact morphometry of the hyoid bone and its relationship with sex and height of the person.

\section{MATERIALS AND METHODS}

This cross-sectional study was conducted in the Department of Anatomy, Jawaharlal Nehru Medical College, Belgaum, South India on 60 hyoid bones (36 male and 24 female) from 2014 to 2016 AD. Fine dissection was performed to removed the hyoid bone from the cadaver. The damaged and abnormal or unfused hyoid bones were excluded from the study. Before dissection, sex and approximate age of the cadaver were recorded. The ethical approval was taken from the department before stating the study.

After collecting the hyoid bones, all the muscles and ligament attached were removed with care using toothed forceps and scalpel and named them for the identification (the hyoid bones from male were named as $\mathrm{M} 1$ to $\mathrm{M} 36$ and the hyoids from female were named as F1 to F24). Digital weighing machine was used to take the wet-weight (on the same day of dissection) and dry-weight (after the bone was fully dried) of each hyoid bone.

The following anthropometric measurements were taken on each hyoid bone after the bone was fully dried by using a digital Vernier Caliper, measuring scale (1-14 in $\mathrm{mm}$ ) and electronic weighing machine (15th and 16th in grams). The different parameters are:

1. Length of the right greater cornu

2. Length of the left greater cornu

3. Length of the right lesser cornu

4. Length of the left lesser cornu

5. Distance between tubercles of greater 
cornu in the midline

6. Distance between internal surfaces of the greater cornua

7. Distance between the bases of lesser

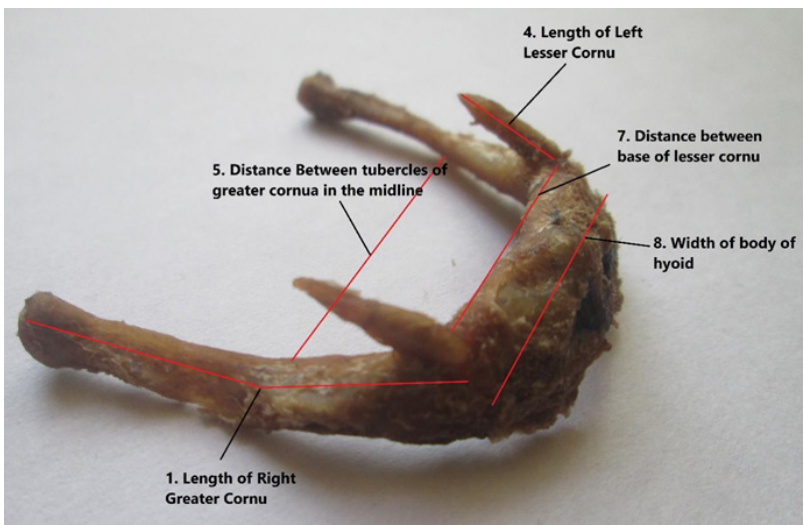

Photograph 1: Parts of Hyoid Bone: Greater and Lesser Cornu, and Body.

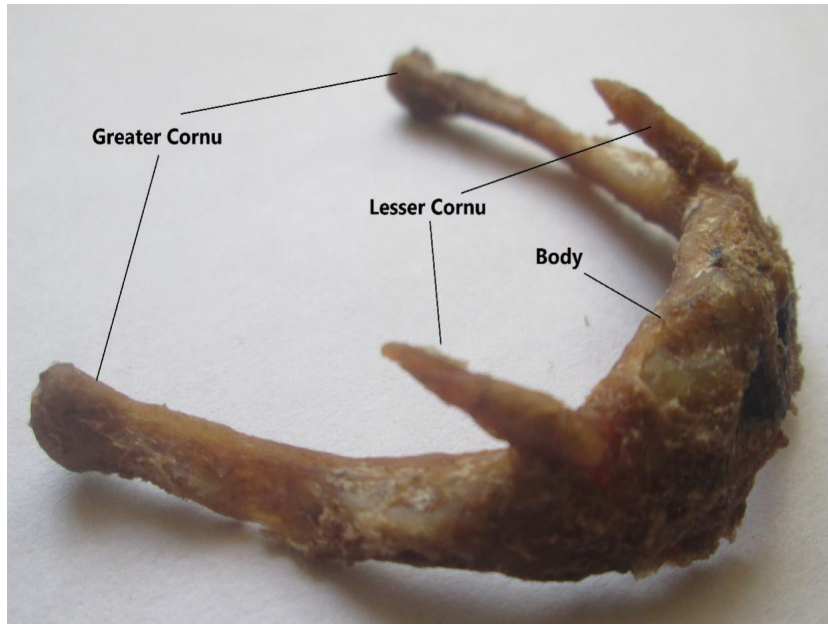

Photograph 2: Anthropometric Parameters of Hyoid bone.

Table 1: Sex wise distribution of the cadavers

\begin{tabular}{|l|c|l|l|l|}
\hline \multirow{2}{*}{ Sex of Cadaver } & Sex of Cadaver & Frequency & Percent/Ranges & P-value \\
\cline { 2 - 5 } & Male & 36 & $60 \%$ & \\
\cline { 2 - 5 } & Female & 24 & $40 \%$ & $<0.05$ \\
\hline \multirow{2}{*}{$\begin{array}{l}\text { Length of cadavers in } \\
\text { cm }\end{array}$} & Male & $165.8+20.4$ & $152-178$ & $141-167$ \\
\cline { 2 - 5 } & Female & $153.6+15.8$ & & \\
\hline
\end{tabular}

cornua.

8. Width (Side to Side length) of the body in the midline

9. Thickness (Antero-posterior) of body in the midline

10. Distance between the upper and lower margins of the body (height).

11. Weight before defating.

12. Weight after defating.

13. Length of the cadaver (from foot to vertex)

The anthropometric parameters of all the 60 hyoid bones were recorded and the data were entered in the SPSS version 16 for further analysis. The data were disseminated in the tabular form and the mean and standard deviation were calculated. The t-test was used as a statistical tool to compare the mean, and Karl Pearson's correlation coefficient was used to find the association between the various anthropometric parameters and the length of cadaver from sole to vertex in supine position (height of the person). The $p$-value of $<.05$ was considered significant.

\section{RESULTS}

The anthropometric parameters of all the hyoid bones were signifacntly more in males than females $(p<0.001)$. The majority of the cadaver $(60 \%)$ were male. Similarly, the length from sole to vertex (height) of the male cadaver in supine position showed strong positive correlation with the width (side to side dimension) of the body in the middle $(r=0.89, p=0.001)$, and thickness (antero-posterior) of body in the middle of hyoid bone $(r=0.78$, $p=0.024$ ) (Table 1).

Overall anthropometric parameters of hyoid bones in males were larger and heavier than in females. There were significant differences in the mean of each anthropometric parameter. The average lenath of right areater cornu $(32.78+2.44)$ in male 
Table 2: Anthropometric Parameters of hyoid bones and its statistical association

\begin{tabular}{|c|c|c|c|c|c|c|}
\hline \multirow{2}{*}{ SN } & \multirow{2}{*}{ Anthropometric parameters } & \multicolumn{2}{|l|}{ Males $(\mathrm{N}=36)$} & \multicolumn{2}{|c|}{ Females $(\mathrm{N}=24)$} & \multirow{2}{*}{$p$-value } \\
\hline & & Mean \pm SD & Range & Mean \pm SD & Range & \\
\hline 1 & Length of right greater cornu & $32.78+2.44$ & $30.5-37.2$ & $28.89+2.47$ & $24.8-32.7$ & $<0.05$ \\
\hline 2 & Length of left greater cornu & $32.67+2.48$ & $30.4-38.6$ & $28.71+2.64$ & $24.6-32.9$ & $<0.001$ \\
\hline 3 & Length of right lesser cornu & $6.42+1.71$ & $4.2-7.5$ & $4.81+0.73$ & $3.5-6.5$ & $<0.001$ \\
\hline 4 & Length of left lesser cornu & $5.94+1.65$ & 4.1-7.4 & $4.53+0.76$ & $4.5-6.8$ & $<0.001$ \\
\hline 5 & $\begin{array}{l}\text { Distance between tubercles of } \\
\text { greater cornu- Middle (central } \\
\text { measurement) }\end{array}$ & $41.89+8.28$ & $31.5-60.5$ & $35.40+5.83$ & $27.6-42.4$ & $<0.001$ \\
\hline 6 & $\begin{array}{l}\text { Distance between internal surfaces } \\
\text { of the greater cornu at their middle }\end{array}$ & $34.25+4.81$ & $22.5-41.3$ & $31.21+2.38$ & $22.6-33.8$ & $<0.001$ \\
\hline 7 & $\begin{array}{l}\text { Minimum transverse distance } \\
\text { between bases of lesser cornua. }\end{array}$ & $20.34+3.82$ & $12.5-27.4$ & $18.45+2.91$ & $11.5-21.6$ & $<0.001$ \\
\hline 8 & $\begin{array}{l}\text { Width (Side to Side length) of the } \\
\text { body in the midline }\end{array}$ & $22.51+3.73$ & $12.5-24.6$ & $20.27+1.75$ & $17.8-22.5$ & $<0.001$ \\
\hline 9 & $\begin{array}{l}\text { Thickness (Antero-posterior) of } \\
\text { body in the middle }\end{array}$ & $6.45+1.79$ & $5.5-9.5$ & $5.66+0.97$ & $4.8-8.5$ & $<0.001$ \\
\hline 10 & $\begin{array}{l}\text { Distance between the upper and } \\
\text { lower margins of the body (height) }\end{array}$ & $12.18+1.38$ & $9.5-15.5$ & $11.21+1.15$ & $8.5-13.5$ & $<0.001$ \\
\hline 11 & ${ }^{* *}$ Weight before defating in gram & $1.858+0.433$ & $\begin{array}{l}1.592- \\
2.271\end{array}$ & $1.261+0.102$ & $0.806-1.851$ & $<0.001$ \\
\hline 12 & Weight after defating & $1.183+0.262$ & $\begin{array}{l}0.782- \\
1.891\end{array}$ & $0.825+0.161$ & $0.478-1.028$ & $<0.001$ \\
\hline 13 & $\begin{array}{l}\text { Length of the cadaver from sole to } \\
\text { vertex }(\mathrm{cm})\end{array}$ & $165.8+20.4$ & $152-178$ & $153.6+15.8$ & $141-167$ & $<0.005$ \\
\hline
\end{tabular}

was greater than in females $(28.89+2.47)$. Similarly, the average length of right lesser cornu $(6.42+1.71)$ in male was greater than in females $(4.81+0.73)$. The Distance between two tubercles of greater cornu in the midline was also greater in male $(41.89+8.28)$ than in females $(35.40+5.83)$. The width (side to side length) of the body of the hyoid bone in the midline was also greater in male $(22.51+3.73)$ than in female $(20.27+1.75)$. The antero-posterior thickness of the body of the hyoid bone in the midline was also greater in male $(6.45+1.79)$ than in female $(5.66+0.97)$. It was also observed that the hyoid bone was heavier in male $(1.858+0.433)$ than in females $(1.261+0.102)$. Other details of findings were presented with mean, standard deviation and range. (Table 2)

\section{DISCUSSION}

Present study evaluated 12 main anthropometric parameters of hyoid bone and the results strongly support the theory that the sexual dimorphism exists in human osteometry. The length of the right greater cornu was slightly greater than the left greater cornu whereas the length of the right lesser cornu is also slightly greater than the left lesser cornu. This finding is supported by priya et al. ${ }^{13}$ and Harjeet et al. ${ }^{14}$

Though there was a non-significant difference in the mean between right and left greater and lesser cornu, sexual dimorphism of their length in male and females was strongly supported. This supports the fact of using length of lesser and greater cornu for the sex determination of unidentifed bonny remains for the forensic scientists. 15,16 
Table 3: Comparison of present study with other study

\begin{tabular}{|c|c|c|c|c|c|c|}
\hline \multirow{3}{*}{$P^{*}$} & \multicolumn{2}{|c|}{ Study done by Priya et al ${ }^{13}$} & \multicolumn{2}{|l|}{ Harjeet et al. ${ }^{14}$} & \multicolumn{2}{|l|}{ Present Study } \\
\hline & Males $(\mathrm{N}=66)$ & $\begin{array}{l}\text { Females } \\
(\mathrm{N}=34)\end{array}$ & Male & Female & Males $(\mathrm{N}=36)$ & Females $(\mathrm{N}=24)$ \\
\hline & Mean \pm SD & Mean \pm SD & Mean \pm SD & Mean \pm SD & Mean \pm SD & Mean \pm SD \\
\hline 1 & $32.58+2.34$ & $28.43+2.34$ & $33.59+2.76$ & $29.79+2.75$ & $32.78+2.44$ & $28.89+2.47$ \\
\hline 2 & $32.37+2.128$ & $28.42+2.32$ & $33.90+2.84$ & $29.66+2.38$ & $32.67+2.48$ & $28.71+2.64$ \\
\hline 3 & $6.04+1.27$ & $4.81+0.73$ & $7.25 \pm 2.05$ & $6.32 \pm 1.53$ & $6.42+1.71$ & $4.81+0.73$ \\
\hline 4 & $5.96+1.36$ & $4.81+0.62$ & $7.05 \pm 1.70$ & $6.42 \pm 1.50$ & $5.94+1.65$ & $4.53+0.76$ \\
\hline 5 & $42.74+8.24$ & $35.00+5.80$ & $41.65+6.32$ & $35.56+5.03$ & $41.89+8.28$ & $35.40+5.83$ \\
\hline 6 & $33.29+4.66$ & $28.02+2.80$ & $33.42 \pm 3.38$ & $27.65 \pm 3.08$ & $34.25+4.81$ & $31.21+2.38$ \\
\hline 7 & $21.71+3.18$ & $18.24+2.9$ & $24.45 \pm 2.35$ & $20.48 \pm 2.42$ & $20.34+3.82$ & $18.45+2.91$ \\
\hline 8 & $23.24+3.07$ & $20.0+1.47$ & $24.03 \pm 2.36$ & $20.29 \pm 1.55$ & $22.51+3.73$ & $20.27+1.75$ \\
\hline 9 & $6.14+1.90$ & $5.60+0.97$ & $6.58 \pm 1.88$ & $5.10 \pm 0.95$ & $6.45+1.79$ & $5.66+0.97$ \\
\hline 10 & $11.85+1.53$ & $10.04+1.01$ & $11.04 \pm 1.10$ & $9.47 \pm 1.08$ & $12.18+1.38$ & $11.21+1.15$ \\
\hline 11 & $1.483+0.393$ & $0.963+0.180$ & $1.84 \pm 0.36$ & $1.19 \pm 0.30$ & $1.858+0.433$ & $1.261+0.102$ \\
\hline 12 & $1.069+0.272$ & $0.759+0.152$ & $1.20 \pm 0.31$ & $0.80 \pm 0.23$ & $1.183+0.262$ & $0.825+0.161$ \\
\hline
\end{tabular}

* Anthropometric Parameters Number in order from above table

The study done by Syeda Sadia Sameera et al. ${ }^{17}$ mean length of right and left greater cornu was $31.93 \pm 3.04$ and $31.13 \pm 4.19$ in males whereas $28.51 \pm 2.69$ and $28.38 \pm 2.49$ in females. Another study done by Nawaz Ahmed S.K. et al. ${ }^{18}$ the mean length of greater cornu in male and female were $31.1 \pm 2,7$ and $27.16 \pm 2.68 \mathrm{~mm}$ respectively. Both of these values were similar to the present study.

The distance between tubercles of greater cornu of hyoid bone in the midline, distance between internal surfaces of the greater cornu at their middle of the hyoid bone and the minimum transverse distance between bases of adjacent lesser cornu of hyoid bone were significantly greater in male than in female. Similar findings were revealed by the study carried out by Reesink et al. ${ }^{6}$ in the Netherlands.

Similarly, the width (side to side length) of the body of each hyoid bone in the midline and the antero-posterior thickness of body of hyoid bone in the midline was significantly correlated with the length of the cadavers from sole to vertex (height of the person). The finding of this study was more impotant in the sex determination from the bony remain for anthropologists as well as forensic scientists. The distance between the upper and lower margins of the body (height) and the weight of hyoid bone before defating and after defating were also greater in male than in female as suggested by various study. ${ }^{10-16}$

The findings of anthropometric parameters of hyoid bone of present study were supported by previous studies conducted by a study done in Korean Cadavers by Kim et al. ${ }^{11}$, North-Indian cadavers by Priya et al. ${ }^{13}$ and Northwest Indian Cadavers by Harjeet et al. ${ }^{14}$. The comparative finding of various other studies with this study is presented in the following table (Table 3).

According to the study done by Harjeet et al. ${ }^{14}$. Priya et al. ${ }^{13}$, Leksan et al. ${ }^{12}$ and Ranjith et al. ${ }^{17}$ the mean weight of the hyoid bone in male was 1.474 $\pm 0.89 . \mathrm{g}$ and that of the female hyoid bone was 0 . $960 \pm 0.33 \mathrm{~g}$. And similar another study conducted 
in Northwest India by Priya et al. ${ }^{11}$, the mean weight after defatting in male hyoids was $1.069 \pm 0.272 \mathrm{~g}$ and in female hyoids it is $0.759 \pm 0.152$ grams, which were statistically significant ( $p$ value $<0.001$ ). In present study the dry weight of male hyoid bone is $1.858+0.433 \mathrm{gm}$ and female hyoid bone was of $1.261+0.102 \mathrm{gm}$, it states that male hyoid bone is heavier than the female's hyoid bones which is in accordance with previous researches. ${ }^{13,14}$ According to the study done by Arash Okasi et al ${ }^{18}$, among the various horns of hyoid bone anthropometry, the length of left great horn is the be indicator for sex identification with $81.7 \%$ accuracy which is similar to the present study.

So, it states that all the parameters considered in the present study were showing significant sexual dimorphism as male hyoid bones were much larger in size when compared to female hyoid bones. These parameters can be considered in forensic investigations for the sex determination of an individual.

In addition to the finding presence of sexual dimorphism supported by various studies, $6,11,13-16$, present study has established the new dimension that the height of a person has strong correlation with the width and thickness of the body of fused hyoid bone. These findings could be useful for the proper identification of the person depending on the height.

\section{CONCLUSION}

The study concluded that all the major anthropometric measurements of hyoid bone were significantly greater in males than in females. Moreover, the height of the person had strong positive correlation with the vertical breadth and transverse length of the body of the hyoid bone. The findings of this study can be of great important for forensic investigation as well as archeological studies.

\section{Acknowledgement}

We extend our sincere thanks to the person who wishes to donate his/her body to the department and all the family members who support and help to fulfill his/her wish.

\section{REFERENCES}

1. Susan Stand ring et al. Gray's Anatomy-The Anatomical, Basis of Clinical Practice. $40^{\text {th }}$ edition, 2008; P: 436.

2. Amgain K. A Textbook of Anatomy and Physiology for Health Sciences. 2nd Edition; Kathmandu, Advanced Ayam Publication; 2019.

3. Ernest Frazer J. The Anatomy of The Human Skeleton, $2^{\text {nd }}$ edition. 1920; P: 271-272.

4. Mehmet Yaşar Işcan, Maryna Steyn, MB. CHB. Textbook of The Human Skeleton in Forensic Medicine. $3^{\text {rd }}$ edition, 2013; P:143.

5. Dnyanesh S, Phaniraj S, Mallikarjun M, Vijayashri $\mathrm{BH}$, Amgain K. Study of Greater Sciatic Notch in Sex Determination of Hip Bone by Metric Method. IOSR Journal of Dental and Medical Sciences (IOSRJDMS). 2013; 10(4):18-23.

6. Reesink EM, Van Immerseel AA, Brand R, Bruintjes TD. Sexual dimorphism of the hyoid bone. International Journal of Osteoarchaeology. 1999;5 : 9357-60.

7. Kindschuh SC, Dupras TL, Cowgill LW. Determination of sex from the hyoid bone. American journal of physical anthropology. 2010;143(2): 279-84.

8. Austin D, King RE. The Biological Profile of Unidentified Human Remains in a Forensic Context. Acad Forensic Pathol. 2016 Sep;6(3):370-90.)

9. Bidmos, Mubarak \& Gibbon, Victoria, Strkalj, Goran. Recent advances in sex identification of human skeletal remains in South Africa. South African Journal of Science. 2010; 106. 1-6. 10.4102/sajs. v106i11/12.238)

10. Miller KW, Walker PL, O'Halloran RL. Age and sexrelated variation in hyoid bone morphology. Journal of Forensic Science. 1998; 43(6): 1138-43.

11. Kim DI, Lee UY, Park DK, Kim YS, Han KH, Kim KH, Han $\mathrm{SH}$. Morphometrics of the hyoid bone for human sex determination from digital photographs. Journal of forensic sciences. 2006; 51(5 : 979-84.

12. Lekšan I, Marcikić M, Nikolić V, Radić R, Selthofer R. Morphological classification and sexual dimorphism of hyoid bone new approach. Collegium antropologicum. 2005;29(1): 237-42.

13. Priya KD, Ranzeetha D. Determination of sex from morphometry of hyoid bone. Indian Journal of Clinical Anatomy and Physiology. 2015; 2(3):157-61.

14. Harjeet J. Shape, size and sexual dimorphism of the hyoid bone in northwest Indians. J Anat Soc India. 1996;45(1): 4-22.

15. Mukhopadhyay P. Morphometric features and sexual dimorphism of adult hyoid bone: A population specific study with forensic implications. Journal of Forensic and Legal Medicine. 2010;17: 321-324.

16. Mukhopadhyay P. Determination of sex from an autopsy sample of adult hyoid bones. Med Sci Law. 52, 2012; P:152-155.

17. Ranjith, Pillai S. A Post mortem study of 100 hyoid bones using weight as parameter. Journal of Indian, Academy of Forensic Medicine. 1988;10:31-33. 
18. Arash Okasi, Mohammad Hossein Sadeghian, Behnam Behnoush and Ali Shakori Rad. Among the various horns of hyoid bone anthropometry. International journal of medical toxicology \& forensic medicine. 2018; 28(4):145-50.

19. Syeda Sadia Sameera, K Ephraim Vikram Rao. Mean length of right and left greater cornu. International Journal of Anatomy and Research.2019; 7(4.1): 703841.

20. Nawaz Ahmed SK, Sreenivasan. Mean length of right and left greater. Indian Journal of Medicine \& Toxicology. 2019;13:4-11.

Forensic 